\title{
As mulheres nas igrejas neopentecostais: a busca pelo protagonismo em meio a tradições hegemônicas
}

\author{
Celso Gabatz \\ Universidade do Vale dos Sinos (Unisinos) - RS \\ gabatz@uol.com.br
}

\begin{abstract}
Resumo A busca pelo protagonismo das mulheres nas denominações neopentecostais é um fenômeno social que tem sublinhado seu envolvimento e sua participação cada vez maiores nas esferas públicas, contribuindo, desta maneira, para a consolidação de uma nova identidade para elas. Os processos de transformação do papel da mulher no âmbito neopentecostal encontram uma resistência vinculada às ideias patriarcais, enraizadas na cultura, e também de gênero, dificultando uma inserção social efetiva para a construção de um imaginário religioso feminino. As novas formas de subjetividade feminina e a construção de identidades de gênero estão ligadas à participação das mulheres e ao seu carisma pessoal, agregando valor ao combate a relações assimétricas entre os gêneros.
\end{abstract}

Palavras-chave: gênero, identidade, neopentecostalismo, subjetividades, poder.

\section{Introdução}

$\mathrm{D}$ acordo com os dados estatísticos apresentados pelo Instituto Brasileiro de Geografia e Estatística (IBGE), o campo religioso brasileiro tem sido palco de uma vertiginosa expansão dos evangélicos. ${ }^{1}$ $\mathrm{Na}$ década de 1940, eles constituíam apenas 2,6\% da população brasileira, mas, desde então, este grupo religioso revelou-se como um dos que mais crescem no Brasil. Progrediu para 3,4\% da população total em 1950, para 4\% em 1960, para 5,2\% em 1970, para 6,6\% em 1980, para $9 \%$ em 1991, para 15,4\% no ano 2000 e para $22,2 \%$ de acordo com o censo realizado no ano de 2010 (Altmann, 2012).

$\mathrm{Na}$ análise da expansão evangélica, destaca-se o papel exercido pelos pentecostais e neopentecostais. Bittencourt Filho (1994) argumenta que o neopentecostalismo alicerça sua proposta religiosa na tríade cura, exorcismo e prosperidade. $\mathrm{Na}$ opinião deste autor, a tríade congregaria fatores sociais e religiosos que respondem às interpretações simbólicas que a população pobre realiza de seus problemas existenciais.

São os velhos princípios socialmente aceitáveis e engendrados pela ordem estabelecida. É oportuno sublinhar que esses valores adestram as pessoas para cumprirem fielmente seus papéis sociais. Disso decorrem as conquistas dos convertidos quanto à restauração de relações familiares e harmonia subjetiva. (Bittencourt Filho, 1994, p. 31-32).

1. O termo "evangélico" é usado aqui para designar o grupo formado pelas igrejas protestantes históricas, pentecostais e neopentecostais. 
A cura através de intervenção religiosa, por exemplo, tem sua importância para a população na medida em que o acesso à saúde é caótico: o serviço público oferece um atendimento deplorável, enquanto o particular é inacessível para a maior parte das classes pobres. Assim, qualquer promessa de cura recebe atenção e esperança. Os dados apontam para um cenário em que a maioria dos seguidores destas Igrejas é composta por mulheres. Entretanto é possível constatar que, apesar de existir nestas denominações uma notável presença de mulheres, não há um claro protagonismo feminino no que diz respeito às decisões e à direção destas igrejas (Machado, 2005).

Esta maior inserção das mulheres decorre da possibilidade de criar espaços alternativos para a discussão dos problemas familiares e femininos, ajudando na recuperação da autoestima e entabulando redes de cooperação e proximidade que possibilitam, entre outras circunstâncias, a entrada no mercado de trabalho (Machado; Mariz, 1997). Além disso, estas Igrejas tratam das aflições humanas, e tais assuntos, na maioria das vezes, encontram-se no âmbito da vida doméstica. Em função disso, cria-se uma situação em que a mulher pode exercer um importante papel como mediadora na relação com o sagrado dentro da família (Birmann, 1996).

Em meio a tradições hegemônicas que colocam os homens em funções estratégicas da vida pública e no exercício de uma autoridade, sempre associada a uma compreensão bíblica que a justifique, a liderança feminina acontece pela suposição de determinadas "habilidades femininas". É comum encontrar as mulheres na direção de escolas bíblicas dominicais e na organização de grupos de oração, louvor e visitação a enfermos e enlutados. Estes papéis são comumente atribuídos às mulheres, sob a orientação de uma liderança masculina que dirige a congregação.

Entre as maiores limitações impostas às mulheres evangélicas, encontra-se o veto, não raro, ao exercício do pastorado, pois este traz consigo a exigência de maior autoridade eclesiástica e, consequentemente, suscita discussões entre líderes das denominações (Santos, 2002). Mesmo que, em algumas igrejas, exista a possibilidade do pastorado feminino, surgem insatisfações decorrentes de uma hierarquia pautada na submissão das mulheres à figura masculina.

O descontentamento de mulheres em denominações que vetam o pastorado feminino transformou-se em campo propício para o surgimento de significativas alterações que refletem um modo de viver a fé de forma alternativa. O neopentecostalismo tem mostrado inúmeros exemplos de mulheres, autoproclamadas pastoras e bispas, rompendo com as demandas anteriores e celebrando em igrejas e espaços adaptados a novas possibilidades cotidianas.

\section{A identidade feminina no meio neopentecostal}

A discussão de gênero sempre preencheu um significativo espaço no âmbito da sociologia, uma vez que o papel social sempre foi definido com base em padrões ou normas de comportamento esperadas daqueles que ocupam determinadas posições na estrutura social (Badinter, 1986). Construções culturais e processos de identidade foram delimitados, desde a antiguidade, por relações de poder que impunham comportamentos aos homens e às mulheres. Estes processos, que nem sempre supunham a coerção física, foram sendo incutidos na subjetividade humana (Eagleton, 2011).

Para o historiador inglês Peter Burke (2002), a ideia de que a masculinidade e a feminilidade são construídas socialmente passou a ser considerada uma questão bastante óbvia. Por este motivo, as discussões acerca de gênero buscavam referir o modo como estas características sexuais eram compreendidas e representadas, ou então como eram trazidas para a prática social e tornadas parte do processo histórico.

Os papéis reservados para cada sexo são construções sociais que envolvem aspectos de dominação subjetiva vislumbrados na chamada "vocação" feminina, em que as mulheres estariam predispostas a aceitar sua submissão como sendo um fator natural inquestionável, imposto sobre seus corpos e sua existência. Tal perspectiva reflete-se na identidade da mulher em nome do "amor" à família e em função de seu papel de mantenedora e promotora do equilíbrio emocional na vida dos homens e de todos os membros da família. Trata-se de obrigações reforçadas, principalmente, pela religião (Bourdieu, 2007).

A cisão de antigas formas de participação e envolvimento comunitário sob a direção dos homens abre a possibilidade de construção de uma nova perspectiva de identidade para as mulheres. Através da fundação de igrejas, mulheres até então submissas a uma hierarquia marcadamente masculina passam a viver sua religiosidade ocupando um papel de destaque, exercendo plenamente a função de comando à frente de um grupo, na sua maioria, feminino (Miranda, 2009). Dentro do processo de ocupação de cargos e funções nas igrejas neopentecostais, a identidade feminina adquire novos contornos, contrastando com a tradicional imagem de uma mulher absolutamente submissa à autoridade religiosa representada pela figura masculina.

Para Ivone Gebara (2000), a teologia cristã sempre foi fortemente marcada por uma estrutura hierárquica e dualista. Mesmo com algumas mudanças para diminuir o abismo existente entre homens e mulheres, de acordo com a autora, a teologia atual assim 
como a formulação dos dogmas, também se formou a partir das experiências dos homens e continua centrada na figura masculina. É o homem que representa a imagem de Deus de modo normativo, enquanto a mulher só pode ser uma figura em segundo grau. Além disso, os textos cristãos tradicionais ainda insistem no papel maternal da mulher e na ocupação do espaço de poder público pelos homens.

$\mathrm{Na}$ história do cristianismo, os eventos ligados a figuras masculinas são considerados mais relevantes, e a própria figura de Deus é pensada como masculina. A construção dos símbolos religiosos cristãos seria prioritariamente masculina, e a obediência seria devida a homens: pais, padres, bispos e outros.

A religião encerra em si mesma um alto índice de contradição. Levando em conta que a mensagem das religiões, em geral, e de modo particular do cristianismo, é garantir a vivência humana a partir dos valores fundamentais de toda existência, parece contraditório que esses mesmos valores tenham podido gerar formas de cumplicidade com a violência social. (Gebara, 2000, p. 156).

De acordo com Gebara, existe uma visão pessimista do ser humano, considerado incapaz de amar e de ser feliz. Restaria, portanto, obedecer. Obedecer assim como Jesus, que se curvou à vontade de Deus até a morte. Com base na imitação desse sacrifício é que se justificaria a obediência feminina. Riane Eisler pondera acerca de passagens bíblicas do Antigo Testamento que reforçam os argumentos apresentados por Gebara:

Conforme se lê no Antigo Testamento, as leis criadas por essa casta masculina dominante definiam as mulheres como propriedade privada dos homens e não como seres humanos livres e independentes. Primeiro pertenciam a seu pai. Depois, pertenciam a seus maridos ou senhores, como também os filhos que gerassem. (Eisler, 2007, p. 151).

Na opinião de Machado (2005), a ética neopentecostal incentivaria valores coadunados com a subjetividade, considerada feminina pela cultura contemporânea, ao contrário da objetividade, que seria masculina. Valores como docilidade, tolerância, dedicação à família, cuidado e carinho com os filhos seriam aspectos inerentes ao feminino. Quando se fala em relações de gênero mais igualitárias dentro do neopentecostalismo, não se fala do ponto de vista do ideário feminista de questionamento do patriarcado; em vez da igualdade nessas relações, haveria, na verdade, uma apropriação seletiva das ideias feministas, em meio a relações ainda bastante assimétricas. Em última análise, caberia ao homem chefiar a família e, à mulher, submeter-se à autoridade masculina.

Moreira (2006) afirma que uma das principais características do neopentecostalismo é o rompimento com o sectarismo e o ascetismo puritano do protestantismo histórico tradicional. Se, por um lado, as igrejas neopentecostais querem fugir das coisas do mundo, através da crítica ao álcool, ao fumo, aos bares etc., por outro lado, há fortes mudanças nesse ideário. Como o autor salienta, a esfera do lazer e do sexo continua sendo vigiada, mas estes já não são interpretados com a mesma carga negativa de antes. O sexo já é entendido como algo prazeroso e que, dentro do casamento, deve ser feito por prazer, e não só para a procriação. As roupas são bem mais liberais que em outras épocas, sendo permitido, por exemplo, o uso de biquínis nas praias, até mesmo com a intenção de salientar as curvas do corpo feminino.

Mendonça (2008) destaca, ainda, a inserção do cristianismo na modernidade através da intervenção midiática e da sacralização do consumo. Este segundo ponto tem relação indiscutível com uma das maiores características do neopentecostalismo: a "teologia da prosperidade", que tornou a fruição do mundo material algo não só aceito, mas até incentivado como uma bênção de Deus. Para o autor, o neopentecostalismo surge no Brasil em um período em que as fronteiras entre o sagrado e o profano tornam-se cada vez mais próximas. As igrejas buscam fugir desta polarização em virtude de uma influência cada vez maior do pensamento secular. Haveria um esforço em adaptar a mensagem bíblica para as novas gerações através de uma sacralização do profano. Isto desembocaria numa relativização da ética do consumo e da noção de santidade.

A autonomia leiga e a concorrência institucional parecem conduzir as igrejas cristãs a uma orientação rumo às marcas da cultura contemporânea de rejeição de tradicionalismo, adoção de antigos processos mágico-religiosos e inserção na lógica de mercado e na cultura das mídias. (Mendonça, 2008, p. 225).

Para Toledo-Francisco (2002), nas igrejas neopentecostais, há um processo acentuado de adequação da visão institucional às representações e experiências dos fiéis no que diz respeito a questões como sexualidade, divórcio, representações de gênero ou papéis sociais na família. Assim, ao mesmo tempo que os fiéis se enquadram numa normatização moral religiosa, eles também causam transformações na posição da própria igreja, readaptando valores do restante da sociedade que anteriormente não eram aceitos pelas igrejas.

O processo de socialização numa igreja sempre é realizado de forma ativa, de modo que o fiel não 
recebe a doutrina sem refletir e se dispor a adaptações. É o que Toledo-Francisco chama de hibridização, uma espécie de apropriação seletiva da cultura do outro - um processo de construção que termina sendo influenciado pelas instituições neopentecostais em constante formação (Tomita, 2006, p. 147-166).

Esta nova visão da moral neopentecostal tem origem na intensificação do trânsito religioso e na concorrência entre as denominações eclesiásticas, aspectos que forçam uma competição ferrenha pelos fiéis e dificultam a regulação e manutenção das pessoas numa mesma denominação (Machado, 2005). Em outras palavras, quem oferece as melhores estratégias de recrutamento tem melhores chances de ver seus cultos cheios. Ou seja, há nas igrejas neopentecostais, de acordo com Machado, uma grande capacidade de selecionar, ressignificar e incorporar elementos de outras religiões, além da disponibilidade para a adaptação à sociedade, culminando numa plasticidade e dinamismo paradoxais.

Estas mudanças no neopentecostalismo só acompanham, na verdade, as mudanças ainda mais profundas ocorridas na sociedade como um todo. Jablonski (1998) lembra que a transformação nas relações de gênero alterou radicalmente as relações dentro da família. Para o autor, a diminuição drástica do número de filhos por casal, como vem acontecendo nas últimas décadas, contribuiu para que o foco do relacionamento seja mais o indivíduo do que a família. A satisfação individual seria mais importante do que as obrigações coletivas. Tais mudanças tornam as relações entre homens e mulheres mais fluidas e o casamento não mais indissolúvel.

A transformação de mulheres submissas em líderes rompe com o estereótipo da mulher servil sustentado por um grupo de igrejas evangélicas pentecostais conhecidas pela rigidez dos usos e costumes - por exemplo, a Igreja Assembleia de Deus, Igreja do Evangelho Quadrangular, Igreja Deus é Amor, Igreja O Brasil para Cristo, entre outras. Da perspectiva adotada por essas denominações, as mulheres não poderiam ir além do comando de escolas bíblicas e da organização de grupos de oração.

Com o rompimento dessa concepção nas denominações neopentecostais, estas conseguem reunir um considerável grupo de seguidoras em torno do carisma das mulheres autoproclamadas bispas e pastoras, que mostram ser possível uma nova configuração da identidade feminina de acordo com parâmetros mais liberais e coadunados com as necessidades imediatas das mulheres nas famílias, na igreja e na sociedade em geral.

\section{Mulheres, sociabilidade e poder eclesial}

De acordo com Giddens (1991), o novo cenário descrito não desperta apenas a impressão de que as sociedades modernas estão se tornando cada vez mais impessoais ou de que vivemos em um período estranho e em contraposição às intimidades da vida pessoal. O que pode ser vislumbrado é que a dialética entre a sociedade contemporânea e as relações impessoais vem suscitando a transformação da natureza humana. As relações sociais e as sociabilidades vão sendo demarcadas por distanciamentos, combinações e novas particularidades.

A cosmologia religiosa é suplantada pelo conhecimento reflexivamente organizado, governado pela observação empírica e pelo pensamento lógico, e focado sobre a tecnologia material e códigos aplicados socialmente. Religião e tradição sempre tiveram uma vinculação íntima, e esta última é ainda mais solapada do que a primeira pela reflexividade da vida social moderna. (Giddens, 1991, p. 122).

Se em grupos tradicionais o pertencimento a uma determinada comunidade já inseria o indivíduo numa rede de sociabilidade e confiança, também nas comunidades neopentecostais as relações de confiança e reciprocidade necessitam ser consolidadas. "A confiança pessoal torna-se um projeto a ser trabalhado pelas partes envolvidas" (Giddens, 1991, p. 127). Assim, as denominações neopentecostais parecem ser ambientes propícios para o projeto reflexivo de construção de redes de sociabilidades. Por se tratar de instituições pertencentes a um contexto em que a confiança não é controlada por códigos normativos fixos, esta necessita ser alcançada através da abertura para o outro e de uma postura de cordialidade, interesse, inserção e empenho demonstrados para com ele. Ainda que as igrejas, na maioria dos casos, sejam ambientes favoráveis a esta abertura, isto não garante a inserção em redes de solidariedade. Estas terão que ser construídas e consolidadas.

Bourdieu (1998) retrata que as instâncias religiosas, em sua luta pelo monopólio do exercício do poder religioso, produziram uma doutrina capaz de conferir um sentido à vida e ao mundo. É nesta perspectiva que a questão da autonomia é um elemento importante e que se reconhece o acesso das mulheres a cargos ou funções estratégicas dentro das igrejas, ainda que de forma limitada. A pesquisadora Fabíola Rohden (1997, p. 83, grifo nosso) faz referência a essa restrição destacando que a "crescente presença das mulheres participando das comunidades leva a que 
seja 'permitido' o acesso de algumas a determinadas posições”.

Weber (1994), por sua vez, argumenta que a participação e o envolvimento das mulheres, enquanto dotadas de carismas, no terreno religioso não significam a sua igualdade nesse terreno. Se as relações são parte do cotidiano e, portanto, regulamentadas pelas instituições, os carismas femininos são, por vezes, compreendidos como contrários à ordem eclesiástica. Segundo Machado (2005), nem sempre as mudanças nas hierarquias eclesiásticas resultam das reivindicações e da pressão das mulheres que integram tais hierarquias. Fatores de outra natureza, como, por exemplo, o acirramento da competição religiosa e o reduzido número de homens para o sacerdócio, podem favorecer a interação feminina.

Na concepção de Michelle Perrot (2006), enxergar a mulher apenas como um objeto de trabalho ou de sexualidade é algo que reduz a figura feminina à condição de serviçal no âmbito masculino. Embora a realidade histórica aponte para a falta de uma autonomia sociocultural, essa visão foi sendo mudada nos últimos anos do século XX. A autora explica que a mulher, na sociedade do terceiro milênio, tem sido mais cobrada para que assuma seu papel de destaque nas relações sociais. Isso implica também sua inserção maior em espaços religiosos. As estratégias de mobilidade e consolidação de um maior protagonismo das mulheres nos espaços das igrejas neopentecostais acontecem mediante a incorporação dessas mulheres em novas habilidades, antes atribuídas somente aos homens. Mesmo em ambientes restritivos como os de organização sacerdotal e de obrigações hierárquicas, surgem novos horizontes de mobilidade social baseados na capacidade pessoal de inovação e empreendimento.

A ocupação de lugares por mulheres através dessa interação, mesmo sob a estrutura patriarcal, talvez já seja um sinal de novas construções das sociabilidades (Souza, 2006, p. 15-20). Trata-se de construções delineadas pela manifestação de ideias que permeiam o imaginário feminino - a exemplo das novas propostas de gestão feminina fora do espaço privado -, contribuindo para uma socialização simbólica na qual as mulheres são situadas em espaços de referência estratégica.

Portanto, pode-se afirmar que as identidades femininas [...] têm mais a ver com a negociação diante de novas rotas de trajetória social do que com as suas raízes de origem, uma vez que esse mundo de origem tende a ser negado mediante o novo ethos religioso. As identidades estão construídas a partir de uma interpretação do mundo, por isso a necessidade de compreendê-las como produtos de um contexto histórico, de práticas discursivas e de uma instituição social específica. [...] [Elas] emergem de um jogo de poder específico com diferenças e exclusões sociais iguais ao mundo mais amplo de mulheres. (Bandini, 2014, p. 125).

As mulheres constroem suas interações e sociabilidades a partir das próprias estratégias e posições sociais adquiridas ao longo de suas trajetórias. Isto implica sua adesão a um eu coletivo que passa a fazer parte da história de um grupo específico e que se estabiliza num pertencimento cultural e religioso (Hall, 2000, p. 108). Esse processo é marcado pela rejeição à emancipação das mulheres, algo decorrente, em certa medida, de um engessamento de sua subalternidade e de uma precária formação teológica. As matrizes da socialização imaginária do papel da mulher perante o marido sugerem uma sintonia com determinadas matrizes cristãs que acentuam o papel da submissão (Rosado Nunes, 2001, p. 79-96). Por isso, outra forma de se justificar esse aspecto de poder sobre as mulheres é o fato de que elas praticamente não possuem um discurso próprio. Assim, há um continuísmo hermenêutico. Algo que caracteriza e amplia a dominação masculina, patriarcal.

O novo papel social representado pelas mulheres, nesse ambiente híbrido de mercadorias e fiéis, pode ser endossado como mais um atrativo a ser oferecido a elas (Mafra, 1998). Corrobora a construção de uma nova subjetividade nos espaços do sagrado e a quebra de paradigmas nas estruturas dos modelos de comunicação, antes processados de forma unilateral.

As mulheres continuam presas a algumas relações de poder e dominação porque suas ações de resistência ainda não removeram as causas estruturais das contradições. Para tal transformação, as mulheres necessitam realizar uma ação mais coletiva e menos individualista, pois enquanto suas práticas cotidianas de acomodação e resistência continuarem no caminho da negociação individual, as relações de poder e dominação de gênero, raça, idade e classe social persistirão. (Bandini, 2014, p. 281).

O neopentecostalismo tende a elaborar a similaridade de comportamentos e cerimônias religiosas com as exigências socioculturais da sociedade moderna, tendo por objetivo inserir-se no contexto social. A preocupação dessa vertente em não se manter à margem do sistema gera a necessidade de renunciar a certos atributos religiosos e adotar padrões seculares, promovendo, desse modo, a "mundanização" da experiência espiritual (Mariano, 1999).

Há negociações permanentes em espaços de heterodoxias nos quais os monopólios de significado se desfazem mediante resistências. Busca-se a homogeneização dos sujeitos e dos sentidos. Daí decorre a eficácia das dominações, pois, de uma forma ou de 
outra, as instituições produtoras de sentido se reforçam. Para Tavares (2002), a proporção de superação do imaginário da subordinação natural das mulheres e da dominação masculina implica muito mais do que transformações aparentes. Nessa mesma direção, Touraine (2007) observa que a realidade contemporânea abriga um leque de mecanismos de produção de significados que tem aberto caminhos de combinações simbólicas múltiplas e desafiado os sistemas de significados (particularmente os religiosos) a mudanças profundas.

\section{As escolhas religiosas e as redefinições das subjetividades}

A perspectiva de redefinição das subjetividades dos atores sociais encontra-se estreitamente ligada às escolhas religiosas, num longo processo de individuação desses atores nas sociedades modernas e pós-modernas. Conforme Machado (2005), na literatura antropológica brasileira, existe o consenso de que a expansão das igrejas evangélicas neopentecostais é uma expressão dessa tendência nas camadas populares.

A decisão de tornar-se evangélico em uma sociedade majoritariamente cristã católica exprime não só uma opção consciente e deliberada do indivíduo, mas também uma tensão entre este e o mundo social mais amplo (Berger; Luckmann, 2012). Tal adesão representa uma ruptura com as expectativas sociais e também uma readequação na biografia do indivíduo. A perspectiva de gênero leva a identificar e melhor compreender que a opção de ingressar nesse movimento religioso resulta de experiências diferenciadas dos homens e das mulheres e pode produzir profundas modificações nas próprias relações de gênero.

A doutrina evangélica neopentecostal enfatiza os valores associados à subjetividade feminina. A conquista de uma autoridade moral pelas mulheres e o fortalecimento de sua autoestima ampliam suas possibilidades de desenvolver atividades que ultrapassam a vida doméstica. As redes de sociabilidade favorecem a individuação feminina. $\mathrm{O}$ engajamento nestes espaços possibilita às mulheres uma maior participação na esfera pública, evangelizando em praças, realizando trabalhos voluntários em presídios, hospitais e entidades filantrópicas, participando de programas religiosos televisivos e radiofônicos e dedicando-se à militância política (Silva, 2008).

No entanto, são múltiplos os recursos discursivos e simbólicos acionados pelas mulheres nesse processo, excedendo, em muito, os da esfera religiosa. As novas formas de subjetividade feminina e a reconstrução das identidades de gênero estão relacionadas com o aumento do nível educacional das mulheres, com a ampliação da participação em atividades remuneradas e com o crescimento do número de separações e da chefia feminina das famílias.

A despeito do combate das lideranças religiosas pentecostais ao movimento de mulheres, as mudanças nas representações dos gêneros nesses segmentos confessionais encontram-se também relacionadas com a tendência de apropriação seletiva de ideias feministas pela sociedade, e em especial pelas instituições culturais brasileiras. (Machado, 2005, p. 390).

As mulheres neopentecostais das camadas populares têm identificado nos valores religiosos que também propugnam o individualismo os elementos que dão sentido à reestruturação de suas condutas, das relações familiares e das expectativas em relação à vida (Machado, 2005). Porém, ainda que fortemente associada à expansão neopentecostal, a tendência de revisão do sistema de autoridade não está circunscrita apenas a este segmento da tradição evangélica. Movimentos em favor da consagração de mulheres nos cargos eclesiásticos podem ser percebidos, também, nas denominações do pentecostalismo clássico, como a Igreja Assembleia de Deus e a Igreja Batista, e nas do protestantismo histórico, a exemplo da Igreja Evangélica de Confissão Luterana no Brasil e da Igreja Metodista (Weiss, 2003).

Se, por um lado, o crescimento das ordenações femininas sugere uma sensibilidade da liderança masculina para os processos de revisão do lugar social das mulheres na sociedade contemporânea, por outro lado, existem resistências à autonomia feminina. E, por conta deste aspecto, há dificuldades em ensejar uma política mais partilhada ou equitativa nas funções administrativas e estratégicas das denominações.

A Igreja Universal do Reino de Deus, por exemplo, embora seja a igreja evangélica com maior porcentagem de mulheres em suas fileiras (aproximadamente $75 \%$ ), apresenta um grande número de "obreiras" (auxiliares dos pastores) e pouquíssimas pastoras em seus quadros, fato que sugere resistências internas ao processo de revisão das relações desiguais de gênero (Oliveira Filho, 2012). O ato de estabelecer características próprias a cada gênero, seja com justificativas sociais, biológicas ou religiosas, funciona como uma estratégia retórica poderosa para se posicionar as pessoas do jeito mais interessante a uma instituição.

Daí o fato de a Igreja Universal do Reino de Deus produzir um discurso que colabora para a adaptação da mulher a uma cultura marcadamente desigual quando se estabelece um recorte por gênero (Bovkalovski, 2005). Por trás do discurso igualitário 
de que todos são filhos de Deus, está implícita "uma disputa não só pelo poder, mas pela manutenção do status já conferido aos homens na cultura ocidental" (p. 194).

Nota-se nos discursos algumas manobras retóricas que dão conta de celebrar as conquistas femininas, ao mesmo tempo que ainda se faz questão de manter as mulheres sob o controle da instituição. Machado e Figueiredo (2002) apontam que esta apropriação seletiva tem a função de elaborar um novo significado para tais demandas, absorvendo algumas delas, mas atenuando seus impactos revolucionários que ameacem romper com os arranjos hierárquicos de gênero.

Enfim, as igrejas neopentecostais buscam conciliar um olhar moderno e outro arcaico sobre as relações de gênero. Ao promover modelos de conduta para as mulheres, elas facilitam uma inserção em repertórios interpretativos que mesclam habilmente o respeito e a valorização das conquistas femininas das últimas décadas com uma defesa do posicionamento mais tradicional da mulher como mãe e esposa.

\section{Considerações finais}

O neopentecostalismo oferece às mulheres a possibilidade de uma reelaboração de suas identidades no âmbito religioso. Ao buscar alternativas de inserção comunitária em posições diferentes daquelas que ensejavam uma submissão irrestrita dentro de uma hierarquia marcadamente masculina, as mulheres passam a ocupar um lugar de importância estratégica dentro de suas igrejas. O reflexo destas mudanças em outras esferas sociais mostra-se numa constante evolução. Acompanhando as tendências que modificam o papel da mulher na sociedade, as obreiras, pastoras e bispas transformam-se não apenas em líderes religiosas, mas também em chefes de família e sujeitos de destaque nas comunidades em que vivem.

As igrejas se utilizam tanto da biologia quanto da Bíblia para produzir uma prática discursiva que atribui a homens e mulheres características essenciais determinadas pela divisão sexual. Estes atributos procuram posicionar a mulher como formada, seja pela natureza, seja pelos mandamentos de Deus, para a maternidade e o casamento. A mulher desejaria instintivamente ser mãe e ocupar o lugar de esposa. Seria este o lugar apropriado para o seu melhor desenvolvimento na sociedade. A mescla de repertórios poderia ser explicada pelo próprio processo de secularização e contrassecularização pelo qual passa a sociedade brasileira. O país tem convivido com estas contradições através de movimentos conservadores que propõem relações de gênero baseadas numa forte hierarquização entre homens e mulheres e também através de movimentos liberalizantes, que promovem uma abertura a novas configurações (Blay, 2002).

As denominações neopentecostais parecem mover-se num esforço estratégico para suscitar rupturas com a rigidez dos usos e costumes e promover uma nova percepção sobre temas polêmicos, como planejamento familiar, sexo, aborto, mercado de trabalho. O universo religioso neopentecostal é marcado por adesões e ressignificações. Mostra-se como um campo bastante privilegiado para compreender e pensar as construções de gênero dentro de uma perspectiva que abarque uma pluralidade nos processos de individualização e protagonismo ensejados por homens e mulheres.

\section{Referências}

ALTMANN, Walter. Censo IBGE 2010 e religião. Horizontes, Belo Horizonte, v. 10, n. 28, p. 1122-1129, 2012.

BADINTER, Elisabeth. Um é o outro: relações entre homens e mulheres. Rio de Janeiro: Nova Fronteira, 1986. BANDINI, Claudirene. Costurando certo por linhas tortas: práticas femininas em igrejas pentecostais. Salvador: Pontocom, 2014.

BERGER, Peter Ludwig; LUCKMANN, Thomas. Modernidade, pluralismo e crise de sentido. 3. ed. Petrópolis: Vozes, 2012.

BIRMANN, Patrícia. Mediação feminina e identidades pentecostais. Cadernos Pagu, Campinas, v. 6, p. 201-226, 1996.

BITTENCOURT FILHO, José. Remédio amargo. In: ANTONIAZZI, Alberto (Org.). Nem anjos nem demônios: interpretações sociológicas do pentecostalismo. Petrópolis: Vozes, 1994. p. 24-33.

BLAY, Eva Alterman (Org.). Igualdade de oportunidades para as mulheres: um caminho em construção. São Paulo: Humanitas, 2002.

BOURDIEU, Pierre. A dominação masculina. Rio de Janeiro: Bertrand Brasil, 2007.

BOURDIEU, Pierre. A economia das trocas simbólicas. São Paulo: Perspectiva, 1998.

BOVKALOVSKI, Etiane Caloy. Homens e mulheres de Deus: modelos de conduta ética da Igreja Universal do Reino de Deus (1986-2001). 2005. Tese (Doutorado em História) - Universidade Federal do Paraná, Curitiba, 2005.

BURKE, Peter. História e teoria social. São Paulo: Editora Unesp, 2002.

DE JESUS, Fátima Weiss. "As mulheres sem tranças”: uma etnografia do Ministério Pastoral Feminino na IECLB. 2003. Dissertação (Mestrado em Antropologia Social) Universidade Federal de Santa Catarina, Florianópolis, 2003. 
EAGLETON, Terry. A ideia de cultura. 2. ed. São Paulo: Editora Unesp, 2011.

EISLER, Riane. O cálice e a espada: nosso passado, nosso futuro. São Paulo: Palas Athena, 2007.

OLIVEIRA FILHO, Paulo Gilberto de. A construção das relações de gênero na mídia da Igreja Universal do Reino de Deus. 2012. Dissertação (Mestrado em Psicologia) Universidade Federal de Pernambuco, Recife, 2012.

GEBARA, Ivone. Rompendo o silêncio: uma fenomenologia feminista do mal. Petrópolis: Vozes, 2000.

GIDDENS, Anthony. As consequências da modernidade. São Paulo: Editora Unesp, 1991.

HALL, Stuart. Identidade e diferença: a perspectiva dos estudos culturais. Org. SILVA, Tomaz Tadeu da.; HALL, Stuart.; WOODWARD, Kathryn. 2. ed. Petrópolis: Vozes, 2000.

JABLONSKI, Bernardo. Até que a vida nos separe: a crise do casamento contemporâneo. Rio de Janeiro: Agir, 1998. MACHADO, Maria das Dores Campos; MARIZ, Cecília. Mulheres e práticas religiosas nas classes populares: uma comparação entre as igrejas pentecostais, as Comunidades Eclesiais de Base e os grupos carismáticos. Revista Brasileira de Ciências Sociais, São Paulo, v. 12, n. 3, 1997.

MACHADO, Maria das Dores Campos; FIGUEIREDO, Fabiana. Religião, gênero e política: as evangélicas nas disputas eleitorais da cidade do Rio de Janeiro. Ciências Sociais e Religião, Porto Alegre: Ed. UFRGS, v. 4, p. 125148, 2002.

MACHADO, Maria das Dores Campos. Representações e relações de gênero nos grupos pentecostais. Revista Estudos Feministas, Florianópolis, v. 13, n. 2, p. 387-396, ago. 2005.

MAFRA, Clara. Gênero e estilo eclesial entre os evangélicos. In: FERNANDES, Rubem César et al. (Org.). Novo nascimento: os evangélicos em casa, na igreja e na política. Rio de Janeiro: Iser, 1998.

MARIANO, Ricardo. Neopentecostais: sociologia do novo pentecostalismo no Brasil. São Paulo: Loyola, 1999.

MENDONÇA, Joêzer de Souza. O Evangelho segundo o gospel: mídia, música pop e neopentecostalismo. Revista do Conservatório de Música UFPEL, Pelotas, v. 1, n. 9, p. 220-249, 2008.

MIRANDA, Fernanda Honorato. Religião e mulher: liderança feminina no pentecostalismo evangélico. 2009. Dissertação (Mestrado em Ciências Sociais) - Universidade Federal do Rio Grande do Norte, Natal, 2009.

MOREIRA, Alberto da Silva. As muitas faces do pentecostalismo. Fragmentos de Cultura, Goiânia: Editora UCG, v. 16, n. 3/4, p. 233-242, 2006.

PERROT, Michelle. Minha história das mulheres. São Paulo: Contexto, 2006.

ROHDEN, Fabíola. Catolicismo e protestantismo: o feminismo como uma questão emergente. Cadernos Pagu, Campinas, v. 8/9, p. 51-97, 1997.

ROSADO NUNES, Maria José Fontelas. O impacto do feminismo sobre o estudo das religiões. Cadernos Pagu,
Campinas, v. 16, p. 79-96, 2001.

SANTOS, Maria Goreth. A mulher na hierarquia evangélica: o pastorado feminino. 2002. Dissertação (Mestrado em Ciências Sociais) - Universidade Estadual do Rio de Janeiro, Rio de Janeiro, 2002.

SILVA, Janine. Lideranças pentecostais femininas: notas sobre a reelaboração da identidade feminina no meio pentecostal e sua influência nas demais esferas sociais. In: ENCONTRO DE HISTÓRIA ANPUH, 8., 2008, Rio de Janeiro. Anais... Rio de Janeiro: Anphu, 2008. p. 1-10. SOUZA, Sandra Duarte. Masculinidade e religião: trajetórias de gênero no Brasil. Mandrágora, São Bernardo do Campo, ano 12, n. 12, p. 15-20, 2006.

TAVARES, Silvana Beline. Relações de gênero na Igreja Universal do Reino de Deus: o discurso de Edir Macedo. 2002. Dissertação (Mestrado em Ciências Sociais) Universidade Estadual de São Paulo, Araraquara, 2002.

TOLEDO-FRANCISCO, Crislaine Valéria. Passagens híbridas: relações de gênero e pentecostalismo. 2002. Dissertação (Mestrado em Sociologia) - Faculdade de Filosofia, Letras e Ciências Humanas da Universidade de São Paulo, São Paulo, 2002.

TOMITA, Luiza Etsuko. O desejo sequestrado das mulheres: desafio para a teologia feminista no século 21. In: SOUZA, Sandra Duarte de (Org.) Ensaios feministas. São Bernardo do Campo: Editora da Universidade Metodista de São Paulo, 2006. p. 147-166.

TOURAINE, Alain. O mundo das mulheres. Petrópolis: Vozes, 2007.

WEBER, Max. Economia e sociedade. Brasília: Editora da UnB, 1994.

WEISS, Fátima. "As mulheres sem tranças": uma etnografia do Ministério Pastoral Feminino na IECLB. 2003. Dissertação (Mestrado em Antropologia) - Universidade Federal de Santa Catarina, Florianópolis, 2003. 


\title{
Women from neo-pentecostal churches: the search for protagonism amongst hegemonic traditions
}

\begin{abstract}
The search for the protagonism of women in neo-pentecostal denominations is a social phenomenon that has underlined an ever growing involvement and participation in the public spheres, thus contributing to the consolidation of a new identity. The transformation processes in the roles of women within the neo-pentecostal scope come across resistance connected to patriarchal ideas rooted in culture, as well as in gender, making an effective social insertion difficult for the development of a feminine religious imaginary. The new forms of female subjectivity and the development of identities of gender are linked to the participation of women and their particular personal charisma, adding value to the battle of asymmetric relations amongst the genders.
\end{abstract}

Keywords: gender, identity, neopentecostal, subjectivities, power.

\section{Las mujeres en las iglesias neopentecostales: la busca por el protagonismo en medio a tradiciones hegemónicas}

\section{Resumen}

La busca del papel de las mujeres en las denominaciones neo-pentecostales es un fenómeno social que ha subrayado una creciente implicación y la participación en las esferas públicas, contribuyendo a la consolidación de una nueva identidad. Los procesos de transformación del papel de la mujer en ámbito neo-pentecostal han encontrado una resistencia vinculada a las ideas patriarcales, arraigadas en la cultura y también de género, obstaculizando una efectiva inserción social para la construcción de un imaginario religioso femenino. Las nuevas formas de subjetividad femenina y la construcción de las identidades de género están vinculadas a la participación de las mujeres y a su carisma personal, agregando valor a la lucha contra las relaciones asimétricas entre los géneros.

Palabras clave: género, identidad, neopentecostalismo, subjetividades, poder.

Data de recebimento do artigo: $23 / 12 / 2014$

Data de aprovação do artigo: 20/03/2017 
